University of Nebraska - Lincoln

DigitalCommons@University of Nebraska - Lincoln

USDA Forest Service / UNL Faculty Publications U.S. Department of Agriculture: Forest Service -National Agroforestry Center

2012

\title{
Investigating the influence of LiDAR ground surface errors on the utility of derived forest inventories
}

\author{
Wade T. Tinkham \\ University of Idaho, tink8633@vandals.uidaho.edu \\ Alistair M.S. Smith \\ University of Idaho, alistair@uidaho.edu \\ Chad Hoffman \\ Colorado State University \\ Andrew T. Hudak \\ Rocky Mountain Research Station, ahudak@fs.fed.us \\ Michael J. Falkowski \\ Michigan Technological University, mjfalkow@mtu.edu \\ See next page for additional authors
}

Follow this and additional works at: https://digitalcommons.unl.edu/usdafsfacpub

Tinkham, Wade T.; Smith, Alistair M.S.; Hoffman, Chad; Hudak, Andrew T.; Falkowski, Michael J.; Swanson, Mark E.; and Gessler, Paul E., "Investigating the influence of LiDAR ground surface errors on the utility of derived forest inventories" (2012). USDA Forest Service / UNL Faculty Publications. 182.

https://digitalcommons.unl.edu/usdafsfacpub/182

This Article is brought to you for free and open access by the U.S. Department of Agriculture: Forest Service -National Agroforestry Center at DigitalCommons@University of Nebraska - Lincoln. It has been accepted for inclusion in USDA Forest Service / UNL Faculty Publications by an authorized administrator of DigitalCommons@University of Nebraska - Lincoln. 


\section{Authors}

Wade T. Tinkham, Alistair M.S. Smith, Chad Hoffman, Andrew T. Hudak, Michael J. Falkowski, Mark E. Swanson, and Paul E. Gessler 


\title{
Investigating the influence of LiDAR ground surface errors on the utility of derived forest inventories
}

\author{
Wade T. Tinkham, Alistair M.S. Smith, Chad Hoffman, Andrew T. Hudak, \\ Michael J. Falkowski, Mark E. Swanson, and Paul E. Gessler
}

\begin{abstract}
Light detection and ranging, or LiDAR, effectively produces products spatially characterizing both terrain and vegetation structure; however, development and use of those products has outpaced our understanding of the errors within them. LiDAR's ability to capture three-dimensional structure has led to interest in conducting or augmenting forest inventories with LiDAR data. Prior to applying LiDAR in operational management, it is necessary to understand the errors in LiDAR-derived estimates of forest inventory metrics (i.e., tree height). Most LiDAR-based forest inventory metrics require creation of digital elevation models (DEM), and because metrics are calculated relative to the DEM surface, errors within the DEMs propagate into delivered metrics. This study combines LiDAR DEMs and 54 ground survey plots to investigate how surface morphology and vegetation structure influence DEM errors. The study further compared two LiDAR classification algorithms and found no significant difference in their performance. Vegetation structure was found to have no influence, whereas increased variability in the vertical error was observed on slopes exceeding $30^{\circ}$, illustrating that these algorithms are not limited by high-biomass western coniferous forests, but that slope and sensor accuracy both play important roles. The observed vertical DEM error translated into $\pm 1 \%-3 \%$ error range in derived timber volumes, highlighting the potential of LiDAR-derived inventories in forest management.
\end{abstract}

Résumé : Le lidar (la détection et la télémétrie par la lumière laser) peut servir à cartographier efficacement la morphologie du terrain et la structure de la végétation. Cependant, le développement et l'utilisation de ces cartes ont devancé notre compréhension des erreurs qu'elles contiennent. La capacité du lidar à cartographier la structure tridimensionnelle de la végétation a suscité un intérêt pour réaliser ou étoffer les inventaires forestiers à l'aide de données lidar. Toutefois, avant d'appliquer le lidar dans la gestion opérationnelle, il est nécessaire de comprendre les erreurs d'estimation des métriques d'inventaire forestier dérivées du lidar (comme la hauteur des arbres). La plupart des métriques d'inventaire forestier dérivées du lidar exigent la création de modèles numériques de terrain (MNT). Comme ces métriques sont calculées à partir de la morphologie du terrain, les erreurs dans les MNT se propagent dans les métriques qui sont produites. Cette étude combine les MNT du lidar et 54 placettes au sol pour étudier comment la morphologie du terrain et la structure de la végétation influencent les erreurs dans les MNT. De plus, nous avons comparé deux algorithmes de classification des données lidar et nous n'avons trouvé aucune différence significative entre leur performance. La structure de la végétation n'exerce aucune influence sur l'erreur des MNT. Par contre, lorsque la pente dépasse $30^{\circ}$, la variation de l'erreur verticale augmente. Ces résultats montrent que ces algorithmes ne sont pas limités par les forêts de conifères à forte biomasse de l'ouest des ÉtatsUnis, mais que la précision du capteur et la pente influencent l'erreur des MNT de façon importante. L'erreur verticale des MNT s'est traduite par une marge d'erreur de $\pm 1-3 \%$ dans les volumes de bois qui ont été calculés. Cette faible marge d'erreur met en évidence le potentiel des inventaires basés sur le lidar pour la gestion forestière.

[Traduit par la Rédaction]

\section{Introduction}

Light detection and ranging (LiDAR) is becoming one of the most effective and reliable means of characterizing surface topography and vegetation structure (Falkowski et al. 2009a). LiDAR is being employed in a variety of research and land management applications, including forest inventory and assessment (Goodwin et al. 2006; Smith et al. 2009), carbon sequestration (Asner 2009), hydrologic channeling (Bowen and Waltermire 2002), glacial monitoring (Aber-

Received 6 August 2011. Accepted 16 December 2011. Published at www.nrcresearchpress.com/cjfr on 15 February 2012.

W.T. Tinkham, A.M.S. Smith, and P.E. Gessler. Department of Forest, Rangeland, and Fire Sciences, University of Idaho, Moscow, ID 83844, USA.

C. Hoffman. Warner College of Natural Resources, Colorado State University, Fort Collins, CO 80523, USA.

A.T. Hudak. USDA Forest Service Rocky Mountain Research Station, Moscow, ID 83843, USA.

M.J. Falkowski. School of Forest Resources and Environmental Science, Michigan Technological University, Houghton, MI 49931, USA. M.E. Swanson. Department of Natural Resource Sciences, Washington State University, Pullman, WA 99164, USA.

Corresponding author: Wade T. Tinkham (e-mail: tink8633@vandals.uidaho.edu). 
mann et al. 2010), among others (Falkowski et al. 2009b; Hudak et al. 2009; Martinuzzi et al. 2009). Broadening interest exists within forest management towards implementing LiDAR data to conduct or augment traditional forest inventories. However, prior to widespread application in operational forest management, it is necessary for land managers to have a detailed understanding of the magnitude and source of error in LiDAR-derived estimates of forest inventory information (e.g., tree height and timber volume).

Digital elevation models (DEMs) are used in many research, education, and resource management applications. All LiDAR-derived metrics, e.g., tree height, depend on accurate DEM creation, as misclassification of points in the DEM will influence the accuracy of vegetation return heights that are used for calculating inventory metrics. This is further confounded given that aboveground point heights are calculated relative to the DEM, and vertical DEM errors propagate to these point heights. As a result, misclassification of the ground directly influences derived metrics such as vegetation height, emphasizing the importance of understanding the variables influencing DEM accuracy (Jensen 2007; Evans et al. 2009). The accuracy of LiDAR-derived DEMs has been researched across a variety of vegetation and terrain types (Tinkham et al. 2011). The majority of these studies, however, have been conducted either at small spatial scales relative to the direct effects of the tree and stand structure or in regions with little topographic relief (Hodgson and Bresnahan 2004; Bowen and Waltermire 2002). In contrast, few studies have been conducted in regions with forest structure and terrain complexity similar to that found in the mountainous western United States (Reutebuch et al. 2003; Hyyppä et al. 2005). Several studies have demonstrated the ability of LiDAR to produce strong correlations between field-measured and LiDAR-estimated tree heights with a slight bias towards underestimation across a variety of conditions (Falkowski et al. 2006). A recent study by Gatziolis et al. (2010) demonstrated that increases in terrain slope lead to decreased LiDAR tree height estimates, in part due to the influence that slope has on DEM accuracy (Gatziolis et al. 2010). The current study looks at a region high in topographic complexity, with elevations ranging from $1100 \mathrm{~m}$ to $2000 \mathrm{~m}$ across small spatial extents $(<2 \mathrm{~km}$ apart), slopes reaching upwards of $70^{\circ}$, and diverse forest systems, ranging from dry Pinus ponderosa habitats to moist Abies concolor habitats (Cooper et al. 1987).

The objectives of this study were $(i)$ to analyze the influence of terrain slope and canopy cover on the vertical accuracy of LiDAR-derived DEMs produced by both an opensource technique and a proprietary technique and (ii) to evaluate the magnitude of impact that DEM errors have on timber volume estimates in a mixed conifer forest of the mountainous western United States.

\section{Background: sources of LiDAR DEM errors}

Many LiDAR acquisition contracts seek to have LiDARderived DEMs meet a minimum vertical accuracy of $0.15 \mathrm{~m}$ root mean square error (RMSE) at a 95\% confidence interval (Evans et al. 2009; Flood 2004); however, validation of DEMs often occurs on flat $\left(<5^{\circ}\right.$ slope), sparsely vegetated areas such as local airports and thus are sometimes also spa-
Fig. 1. Illustration of the potential influences of horizontal error and slope on vertical accuracy of discrete LiDAR return positions. Image adapted from Hodgson and Bresnahan (2004).

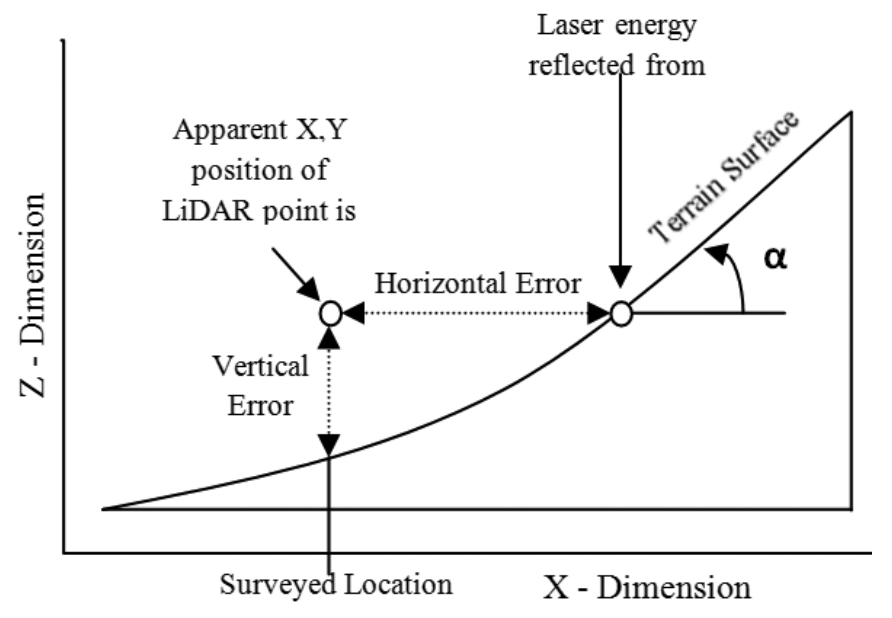

Elevation Error $=\tan \alpha *$ Horizontal Displacement

tially disconnected from the area being studied ( $\mathrm{Su}$ and Bork 2006; Aguilar and Mills 2008). Independent field studies have found absolute vertical accuracies of $0.17 \mathrm{~m}$ to $0.26 \mathrm{~m}$ RMSE when looking at areas of flat slope $\left(<5^{\circ}\right)$ and varying vegetation structures (Hodgson and Bresnahan 2004), while other studies have found RMSEs of $0.27 \mathrm{~m}$ for low slopes $\left(<30^{\circ}\right)$ and $0.58 \mathrm{~m}$ for steep slopes $\left(>30^{\circ}\right.$ ) (Takahashi et al. 2005). The observed horizontal error directly leads to vertical error within DEM surfaces (Hodgson and Bresnahan 2004). Furthermore, as terrain slope increases, the level of vertical error in a LiDAR-derived DEM increases (Hyyppä et al. 2005; Bates and Coops 2009). This relationship between slope and vertical accuracy is known to be influenced by the amount of horizontal error in the LiDAR system, as demonstrated by the relationship in Fig. 1 (Hodgson and Bresnahan 2004). This relationship occurs because of the built-in horizontal error of the LiDAR collection system, resulting from the aircrafts' global positioning system, inertial navigation unit, and inertial measurement unit systems. For instance, a horizontal displacement of $0.50 \mathrm{~m}$ parallel to a $10^{\circ}$ slope will cause a vertical error of $\pm 0.09 \mathrm{~m}$, whereas a $0.50 \mathrm{~m}$ horizontal displacement parallel to a $30^{\circ}$ slope will cause a vertical error of $\pm 0.29 \mathrm{~m}$. However, horizontal displacements that are perpendicular to the slope or along a single contour will not influence the vertical error regardless of slope level.

The impacts of sensor elevation on pulse density, number of returns per square metre, and LiDAR-derived DEM accuracy have been investigated in several studies. These studies have shown that as flight altitude increases, the percentage of pulses that penetrate the forest canopy is reduced due to the broadening of the pulses' footprint and thus the weakening in its energy (Goodwin et al. 2006; Hyyppä et al. 2005). This reduction in pulse density and penetration rate increases the planimetric error, which significantly increases DEM vertical error. However, it has been shown that point density does not need to exceed the scale of the desired surface 
model, which means that if a DEM with $1 \mathrm{~m}$ cells is desired, the necessary ground return density is 1 point $\cdot \mathrm{m}^{-2}$ (Liu et al. 2007). Although the impact of flight altitude on posting density and DEM accuracy has been thoroughly studied, the effect of flight altitude within a single LiDAR acquisition in high-relief terrain has not been investigated.

The influence of vegetation on DEM accuracy has been studied in a wide array of vegetation structures ( $\mathrm{Su}$ and Bork 2006; Bates and Coops 2009; Tinkham et al. 2011). Su and Bork (2006) investigated the DEM accuracy in aspen parklands and found vegetation to be the greatest source of error in LiDAR-derived DEMs. Tinkham et al. (2011) showed DEM accuracies to vary from RMSEs of $0.13 \mathrm{~m}$ in forb meadows to $0.30 \mathrm{~m}$ under coniferous forest canopies in a mixed shrub steppe and woodland ecosystem. Within a multi-use area of coniferous forest, it was documented that variation in structure (pole-sapling, young forest, and old forest) lead to fluctuations in DEM accuracy from $0.10 \mathrm{~m}$ to $0.18 \mathrm{~m}$ (Bates and Coops 2009). Although several studies have investigated the direct impact that forest vegetation has on vertical accuracy of DEMs, few have looked at the impact on accuracy directly at the base of a tree, which would affect subsequent tree height estimates derived from the LiDAR. One study noted that there was an increase of $0.05 \mathrm{~m}$ in error directly at the base of spruces when compared with the accuracy found in canopy gaps (Picea spp.; Hyyppä et al. 2005). This is believed to be because of the scattering effect that forest canopy has on the laser pulse, causing a reduced posting density (Disney et al. 2010). However, few field studies have examined the influence of complex multistory coniferous forests on LiDAR-derived DEM accuracy.

In summary, the relationships that exist between LiDARderived DEM accuracy and terrain slope, flight altitude, and vegetation structures are well documented; it is understood that these variables all directly impact the accuracy of DEMs. However, there remains a need to understand how different LiDAR point classification algorithms influence these terrain and vegetation variables in the production of DEMs. Many of the point classification algorithms being applied by commercial vendors within the industry are often considered proprietary techniques and are often grey- or black-box approaches, limiting their validation by third parties. Recently, however, open-source point classification algorithms have become more reliable and readily available. With the availability of open-source algorithms, it is possible to compare products generated by the LiDAR consumer with those being produced by LiDAR vendors. One of these openly available algorithms specifically developed for conditions similar to the high-biomass and structurally complex forest seen in this study is the multiscale curvature classification (MCC) LiDAR algorithm (http://sourceforge.net/projects/ mcclidar).

\section{Methods}

\section{Study area}

The study area $\left(107 \mathrm{~km}^{2}\right)$ is contained within four forested blocks in central Idaho (USA) around the town of McCall (Fig. 2), with undulating mountainous terrain ranging in elevation from $1100 \mathrm{~m}$ to $2000 \mathrm{~m}$. Slopes in the region range from $0^{\circ}$ to upwards of $70^{\circ}$, and the lowest and highest eleva- tions within the study area are only $2 \mathrm{~km}$ apart. Field plots were distributed from $1200 \mathrm{~m}$ to over $1700 \mathrm{~m}$ and on slopes from $0^{\circ}$ to $50^{\circ}$. Table 1 summarizes the range of structural variables that were analyzed. Second-growth coniferous forests dominate the area, with intermittent patches of savannah and shrub steppe. Common tree species in the area include ponderosa pine (Pinus ponderosa Dougl.), Douglas-fir (Pseudotsuga menziesii var. glauca), grand fir (Abies grandis Dougl.), lodgepole pine (Pinus contorta Dougl.), Engelmann spruce (Picea engelmannii Parry), and western larch (Larix occidentalis Nutt.) (listed in descending order according to basal area dominance), while the shrub steppe is primarily comprised of basin big sagebrush (Artemisia tridentata var. tridentata) (Hitchcock and Cronquist 1979).

\section{LiDAR acquisition}

The LiDAR acquisition was conducted in September of 2008. Flight parameters, including pulse frequency, flight speed, and sensor altitude, were optimized to create a nominal pulse density of 1-3 returns $/ \mathrm{m}^{2}$. All processing and point classification of the raw LiDAR performed by the vendor was done utilizing the Terrasolid suite of software for LiDAR processing. The vendor-provided DEM was produced using TerraModeler (Terrasolid Ltd., Jyväskylä, Finland). The TerraScan is a bottom-up ground classification process that operates by applying a progressive TIN (triangular irregular network) densification algorithm (Axelsson 1999). The process starts by selecting localized low points that are the minimum elevation in a user-defined window size; these low points are used for the creation of the first TIN surface. The model then takes the user-defined terrain angle, iteration distance, and iteration angle to test unclassified points. The terrain angle is the maximum terrain angle allowed within the model. Iteration distance and iteration angle are the evaluation criteria that determine the classification of a point. For a point to be classified as ground, it must be within a maximum distance above the TIN surface and not exceed a maximum angle between it and the nearest point classified as ground. If a point is classified as being ground, it is incorporated into the TIN surface, and the next point is subsequently evaluated.

Evans and Hudak (2007) developed the MCC algorithm to classify LiDAR point clouds in high-biomass forests with complex terrain. The MCC algorithm is a top-down classification technique, which operates by discarding returns that exceed a threshold curvature calculated from a surface, interpolated using a thin-plate spline. This is performed through three successively larger scale domains that define the processing window size. The algorithm iterates until the number of remaining returns changes by $<1 \%,<0.1 \%$, and finally $<0.01 \%$ for the three scale domains, respectively.

The performance of any classification algorithm will vary as a function of LiDAR point density and distribution, as well as the topographic and canopy characteristics of the scene. For peak performance, the MCC algorithm requires two parameters to be inputted by the user: scale domain and curvature threshold (Evans and Hudak 2007). An optimization procedure was used in selecting which scale and curvature parameters from MCC would provide the most accurate DEM. The final surface created using the MCC algorithm was produced by a double classification of the raw point 
Fig. 2. Location map of LiDAR study area and plot locations in central Idaho, near the town of McCall. All study blocks are shown in hillshade to give perspective of topographic relief.

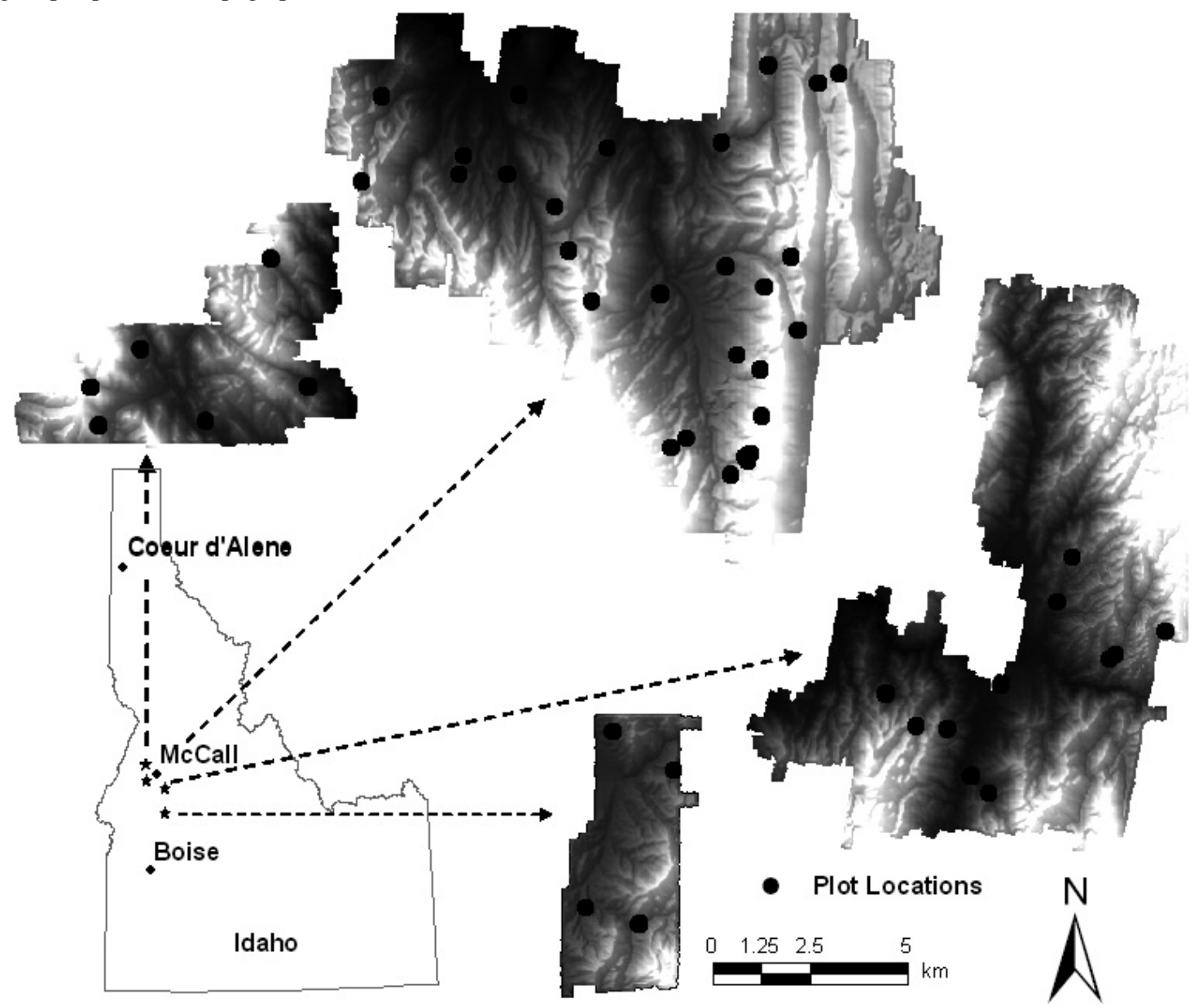

Table 1. Summary of plot-level variables for data collected from plots within four study blocks near McCall, Idaho.

\begin{tabular}{|c|c|c|c|c|c|c|c|c|c|}
\hline & $\begin{array}{l}\text { Elevation } \\
(\mathrm{m})\end{array}$ & $\begin{array}{l}\text { Slope } \\
(\%)\end{array}$ & $\begin{array}{l}\text { Canopy } \\
\text { cover }(\%)\end{array}$ & $\begin{array}{l}\text { Shrub } \\
\text { cover }(\%)\end{array}$ & $\begin{array}{l}\text { No. of } \\
\text { trees } \cdot h^{-1}\end{array}$ & $\begin{array}{l}\text { BA } \\
\left(\mathrm{m}^{2} \cdot \mathrm{ha}^{-1}\right)\end{array}$ & $\begin{array}{l}\text { QMD } \\
(\mathrm{cm})\end{array}$ & SDI & $\begin{array}{l}\text { Canopy } \\
\text { biomass } \\
\left(\mathrm{kg} \cdot \mathrm{m}^{-2}\right)\end{array}$ \\
\hline Mean & 1526 & 24 & 60 & 44 & 321 & 20.1 & 27.5 & 152 & 2.11 \\
\hline Median & 1548 & 25 & 68 & 40 & 272 & 21.6 & 27.8 & 154 & 2.11 \\
\hline $\mathrm{SD}$ & 148 & 13 & 22 & 32 & 247 & 13.7 & 8.1 & 102.4 & 1.47 \\
\hline Maximum & 1734 & 50 & 85 & 95 & 1038 & 50.6 & 51.2 & 352 & 5.30 \\
\hline Minimum & 1223 & 1 & 1 & 0 & 0 & 0.0 & 0.0 & 0 & 0.00 \\
\hline
\end{tabular}

Note: $n=49$ plots; BA, basal area; QMD, quadratic mean diameter; SDI, Reineke's stand density index; SD, standard deviation.

cloud. This double classification allows the algorithm to process the data twice, the first processing removes more than $90 \%$ of the vegetation and the second classification removes the remaining low-level vegetation (i.e., shrubs). The process was performed by classifying the point cloud with the algorithm once and then reclassifying just those points designated as being ground returns in the first classification. For this data set, a scale value of 2.0 and curvature of 0.50 were found to be optimal for the first filtering and a scale of 3.0 and curvature of 0.20 for the second filtering. No manual editing of the point cloud was performed.

\section{Reference data}

The sampling strategy was designed to test the accuracy of
LiDAR-derived DEMs at a fine spatial scale relevant to forest inventory studies (i.e., standard 0.04 ha forest inventory plot; Fig. 3). A system of fifty-four 0.04 ha fixed-radius forest inventory plots (radius $=11.35 \mathrm{~m}$ ) were allocated across the study area in the summer of 2009. To ensure that the study captured the regions' structural variation, the plots were stratified and allocated along gradients of elevation, slope, aspect, and canopy cover. Eligible combinations of the study variables were randomly selected from a modeled map of canopy cover and a U.S. Geological Survey $10 \mathrm{~m}$ DEM. The canopy cover map was created using linear spectral unmixing (Drake et al. 1999; Wessman et al. 1997) in the same manner as conducted by Smith et al. (2009) and applied to an independent Landsat data set calibrated to planetary reflectance 
Fig. 3. Four 0.04 ha (11.35 m radius) field survey plots. Upper left figure is the idealized plot design. The other three figures are examples of field plots collected, points are coded by elevation, and the tree symbols are scaled to represent their diameter at breast height.

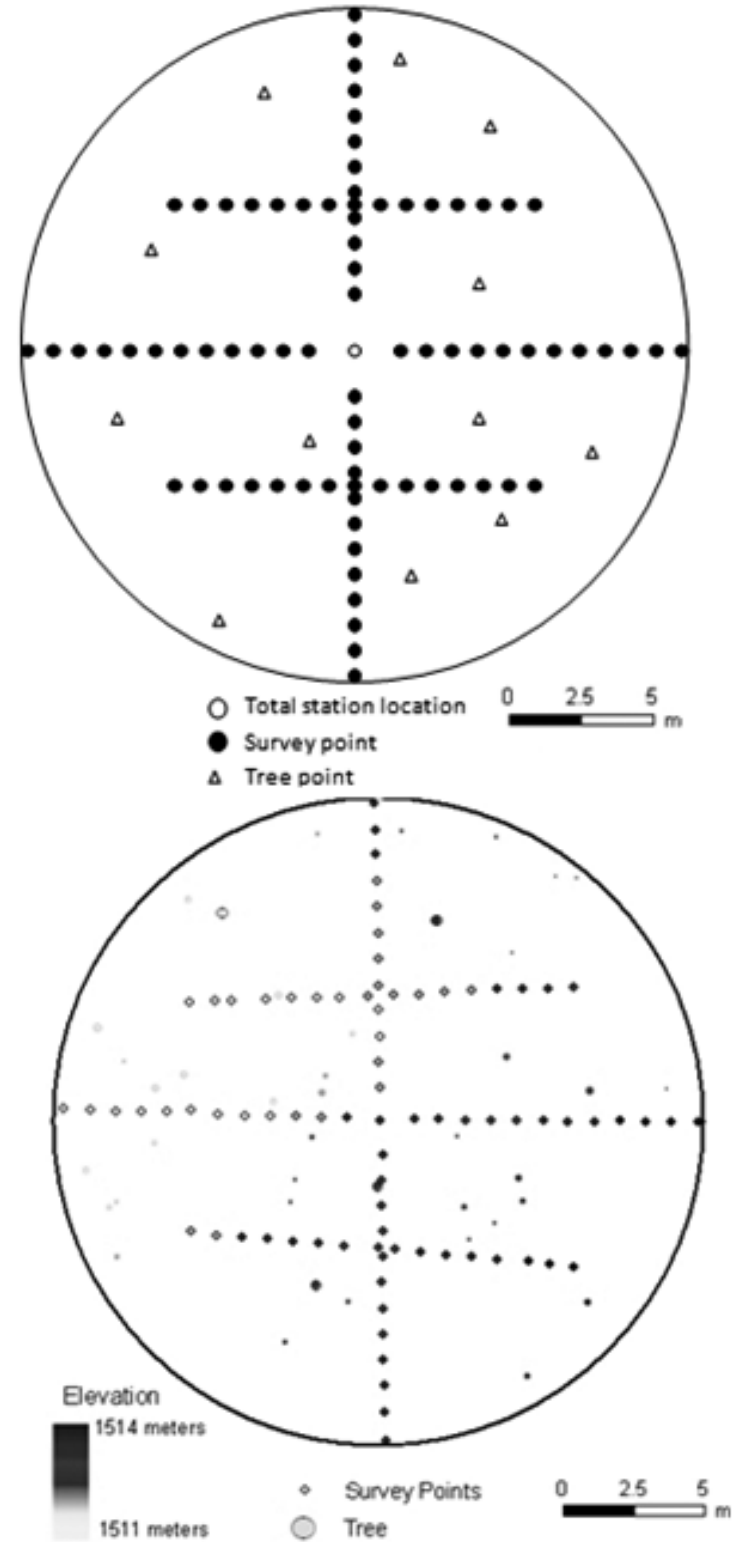

(Landsat 5, 25 July 2008, path 42, row 29). Following past studies (Theseira et al. 2003), end members used in the unmixing process were selected via identification of the pixels corresponding to the vertices produced by plotting values of the principal component analysis images produced in ENVI (IDL, Boulder, Colorado) against each other. The plots were equally distributed across the range of stratification variables, including elevation $(1100-2000 \mathrm{~m})$, slope $\left(0^{\circ}-50^{\circ}\right)$, two aspects (oriented $30^{\circ} \mathrm{NNE}$ and $210^{\circ} \mathrm{SSW}$ ), and canopy cover $(0 \%-100 \%)$ ranges. This stratification helped to ensure a sufficient plot distribution across the primary environmental gradient of conditions in this landscape. Five plots were later excluded from the analysis because they fell just outside the extent of the delivered DEM, which was slightly more limited in extent than the boundary tiles in a "shapefile" used for the stratification (Fig. 2). The sampling design enabled us to analyze whether the DEM overly simplified microtopo-
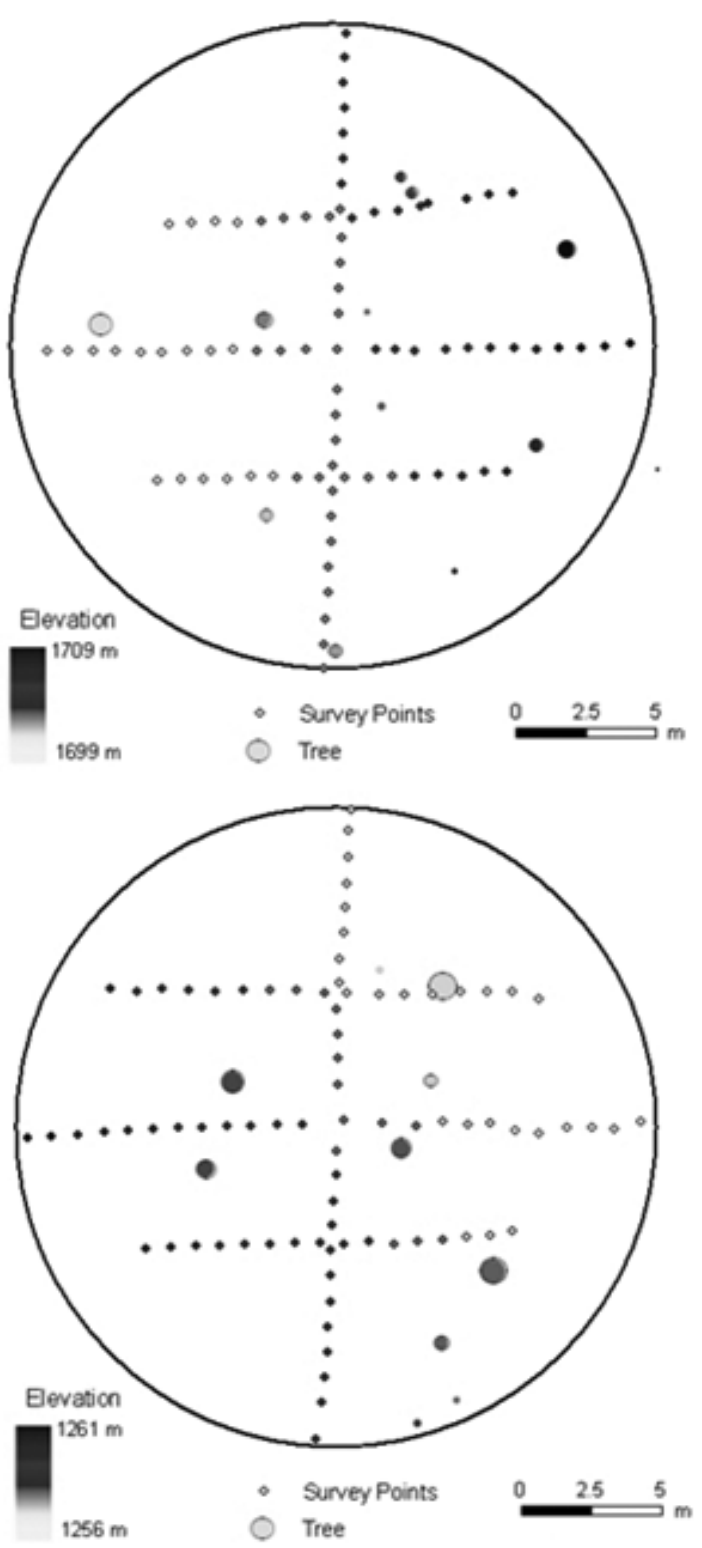

graphic fluctuations (i.e., corresponding to 0.04 ha plots) within the landscape used in this study.

Within each plot, a Topcon GTS-236w (Topcon Corp., Livermore, California) laser total station was used to survey a grid of $\sim 80$ points $(x, y, z)$ and the location of each tree $(\mathrm{DBH}>10 \mathrm{~cm})$ within the plot. The total station's position was georeferenced using a Topcon Hyper-Ga (Topcon Corp., Livermore, California) real-time kinetic (RTK) global positioning system, with static reading standards of $\pm 15 \mathrm{~mm}$ vertical and $\pm 10 \mathrm{~mm}$ horizontal. Locations of the RTK points were limited to gaps in the forest canopy ( $>20 \mathrm{~m}$ radius) to limit the influence of vegetation on survey accuracy. Individual tree data collected included species, diameter at breast height (DBH, $1.37 \mathrm{~m}$ ), total height, height to live crown, and crown diameter for all trees within each plot using a laser Impulse 360 hypsometer (Laser Technology, Inc., Englewood, Colorado). In total, 3948 survey points were taken in the 
Table 2. Summary of plot-level performance of TerraModeler (Vendor) and multiscale curvature classification (MCC) algorithms.

\begin{tabular}{lccllll}
\hline & $\begin{array}{c}\text { MCC } \\
\text { mean }\end{array}$ & $\begin{array}{l}\text { Vendor } \\
\text { mean }\end{array}$ & MCC SD & Vendor SD & $\begin{array}{l}\text { MCC } \\
\text { RMSE }\end{array}$ & $\begin{array}{l}\text { Vendor } \\
\text { RMSE }\end{array}$ \\
\hline Mean & 0.060 & 0.002 & 0.261 & 0.251 & 0.324 & 0.274 \\
Median & 0.055 & -0.006 & 0.218 & 0.187 & 0.250 & 0.194 \\
SD & 0.220 & 0.137 & 0.207 & 0.184 & 0.237 & 0.198 \\
Maximum & 0.665 & 0.530 & 1.149 & 1.181 & 1.321 & 1.288 \\
Minimum & -0.510 & -0.241 & 0.077 & 0.112 & 0.096 & 0.117 \\
\hline
\end{tabular}

Note: All measurements are reported in metres; SD, standard deviation; RMSE, root mean square error.

plot grids, along with the measurements and locations of 636 trees.

The LiDAR products were delivered in State Plane NAD 1983 Idaho West FIPS 1103 feet, whereas the field data were collected using UTM WGS84 Zone 11 North coordinates, with both data sets using the North American Vertical Datum of 1988. The CORPSCON software, which was developed by the U.S. Army Corps of Engineers, was utilized for performing the necessary transformation of the horizontal datums, projecting all of the field data to the aforementioned State Plane system. The transformation was verified through ocular comparison of the surveyed tree locations and aerial photographs.

\section{Calculation of vegetation metrics}

With the individual tree measurements that were collected at each plot, standard forestry metrics, including trees per hectare, basal area per hectare, quadratic mean diameter (QMD), and Reineke's stand density index (SDI), were calculated for each plot. Species-specific tree structure and biomass equations for the central Idaho region were used to estimate individual tree crown densities (branch and foliar mass $\left(\mathrm{kg} \cdot \mathrm{m}^{-3}\right)$ ) and canopy biomass $\left(\mathrm{kg} \cdot \mathrm{m}^{-2}\right)$ for each plot, using the allometrics derived by Brown et al. (1977). Using the Forest Service's gap light analysis (GLA) software (Frazer et al. 1999) and hemispherical fisheye photographs collected with a Nikon E990 using a Nikon Fisheye Converter FC- E8, estimates of canopy cover were obtained in the field. The plot-level variables are summarized in Table 1. The stand successional stage selected for modeling the effect of slope-introduced error on LiDAR timber volume estimates were derived from four study plots that represented, through their trees per hectare and quadratic mean diameter, different successional stages of forest development. The volume estimation calculations were performed using species and region appropriate volume equations from the USDA Forest Service's National Volume Estimator Library (NVEL). Both the Rustagi profile model (Rustagi and Loveless 1991) and the Flewelling profile model (based on unpublished work in 1993 by J.W. Flewelling and L.M. Raynes) were applied utilizing the field-measured tree characteristics.

\section{Statistical analysis}

The corresponding LiDAR elevations were extracted from the DEMs for comparison with surveyed field points. The two elevation data sets, the field survey point elevations, and the extracted DEM elevations were paired, and an elevation difference was calculated for each pairing:
[1] LiDAR $_{\text {elevation }}-$ Survey $_{\text {elevation }}=$ Difference $_{\text {elevation }}$

Within each plot the mean, standard deviation, and root mean square error (RMSE) of the differences were calculated for all of the pairings. The plot-level performance of the two algorithms is summarized in Table 2.

Preliminary plot-level analysis was done using a forward stepwise linear regression to investigate which variables significantly influence the vertical accuracy of these two LiDAR classification algorithms. All variables used in the stepwise regression analysis were tested for multicollinearity between the variables using a Pearson correlation matrix. When two variables were found to be strongly correlated $(r>0.8)$, the variable with the strongest correlation with the dependent variable was kept and the weaker variable was discarded. Significant variables were further individually tested to see if other regression functions would improve the amount of variability they accounted for.

To further investigate this variability and relationship of terrain slope and any potential interactions with the algorithms or canopy cover on DEM accuracy, a three-way ANOVA was applied, with the plots grouped into four arbitrary defined slope classes $\left(0^{\circ}-10^{\circ}, 11^{\circ}-20^{\circ}, 21^{\circ}-30^{\circ}\right.$, and $\left.>30^{\circ}\right)$ and three equal fractional canopy classes $(0 \%-33 \%, 34 \%-$ $66 \%$, and $67 \%-100 \%$ ) (Table 3). To pass both the ShapiroWilk normality test and the Levene test of equal variance, it was necessary to apply a log-scale transformation to the vertical RMSEs from both data sets. Significant differences $(\alpha=$ 0.05 ) between LiDAR elevations, slope, and canopy cover were identified using a Tukey honest significance test. This analysis allowed for comparison of changes in RMSE accuracy due to terrain and vegetation conditions both within and across algorithms (i.e., MCC and TerraModeler).

\section{Results and discussion}

When analyzing the plot RMSE as the dependent variable in the linear stepwise regression, slope was the only significant variable returned, with MCC slope and TerraModeler slope returning $r^{2}$ of 0.234 and 0.199 , respectively $(p<$ $0.05)$. Slope was further investigated to see if some other regression relationship could be found to improve its predictive ability; using an exponential regression, an $r^{2}$ of 0.284 and 0.300 was achieved for MCC and Vendor algorithms, respectively (Fig. 4). As can be seen in Fig. 4, the level of variability in LiDAR vertical accuracy increases as the terrain slope increases; however, the random nature of how slope interacts with a particular LiDAR pulse limits the usefulness of regression analysis. Figure 5 shows that for both algorithms there is 
Table 3. Three-way ANOVA of algorithm (filter), slope classes, and canopy cover classes against plot-level RMSE $(\alpha=0.05)$.

\begin{tabular}{lrllrr}
\hline Source of variation & df & SS & MS & \multicolumn{1}{l}{$F$} & \multicolumn{1}{l}{$P$} \\
\hline Algorithm & 1 & 0.066 & 0.066 & 1.449 & 0.233 \\
Slope & 3 & 1.459 & 0.486 & 10.739 & $<0.001$ \\
Canopy & 2 & 0.011 & 0.006 & 0.126 & 0.882 \\
Filter $\times$ slope & 3 & 0.007 & 0.002 & 0.055 & 0.983 \\
Filter $\times$ canopy & 2 & 0.044 & 0.022 & 0.487 & 0.617 \\
Slope $\times$ canopy & 6 & 0.352 & 0.059 & 1.296 & 0.270 \\
Filter $\times$ slope $\times$ canopy & 6 & 0.100 & 0.017 & 0.369 & 0.896 \\
Residual & 74 & 3.352 & 0.045 & & \\
Total & 97 & 5.616 & 0.058 & & \\
$\quad$ Note: RMSE, root mean square error; df, degrees of freedom; SS, sum of squares; MS, mean \\
square.
\end{tabular}

Fig. 4. Exponential regression of DEM accuracy at the plot level.

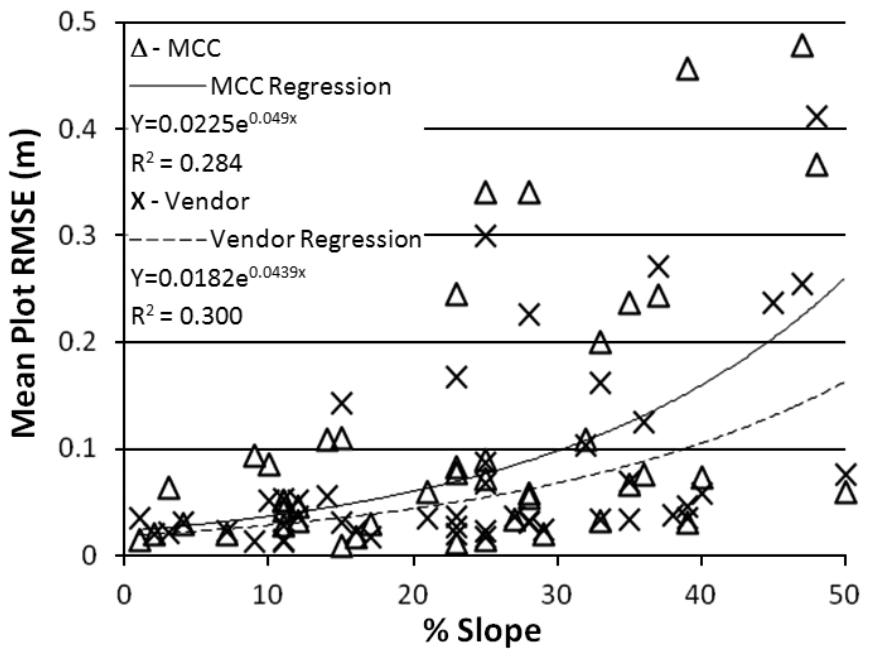

a significant increase in the plot-level RMSE for plots located on slopes greater than $30^{\circ}$ (slope class 4 , plots in the $30^{\circ}-$ $50^{\circ}$ range). This implies that in areas of slope $>30^{\circ}$, a significant increase in the vertical RMSE DEM accuracy should be expected. This relationship between slope and vertical accuracy was observed for both algorithms.

The influence of slope on DEM accuracy is one of the most thoroughly investigated variables in LiDAR research, from detailed studies that just investigated low slopes $\left(<10^{\circ}\right)$ (Hodgson et al. 2005) to studies that have looked at wideranging slopes $\left(0^{\circ}\right.$ to $>30^{\circ}$ ) (Hyyppä et al. 2005). Although the effect that slope has on DEM accuracy has been investigated, the nature of how slope influences LiDAR vertical error accuracy remains random and unpredictable. This random nature is because there is no predictive relationship to tell if a pulse will travel parallel or perpendicular to a slope. Within this study, a poor correlation was found by both the stepwise linear regression and the exponential regression between slope and plot RMSE. Although the ANOVA analysis allowed the variability in vertical accuracy seen at increased slopes to be captured by slopes exceeding $30^{\circ}$, this finding is comparable with other accuracies reported for studies in similar environments (Hodgson and Bresnahan 2004; Takahashi et al. 2005). All of these studies agree that the greater the terrain slope is, the greater the vertical error in the DEM. This study demonstrates that there is an increase in variabil-
Fig. 5. DEM accuracy within four slope classes, as indicated by the three-way ANOVA. Inset letters represent significant changes in accuracy at the $\alpha=0.05$ level.

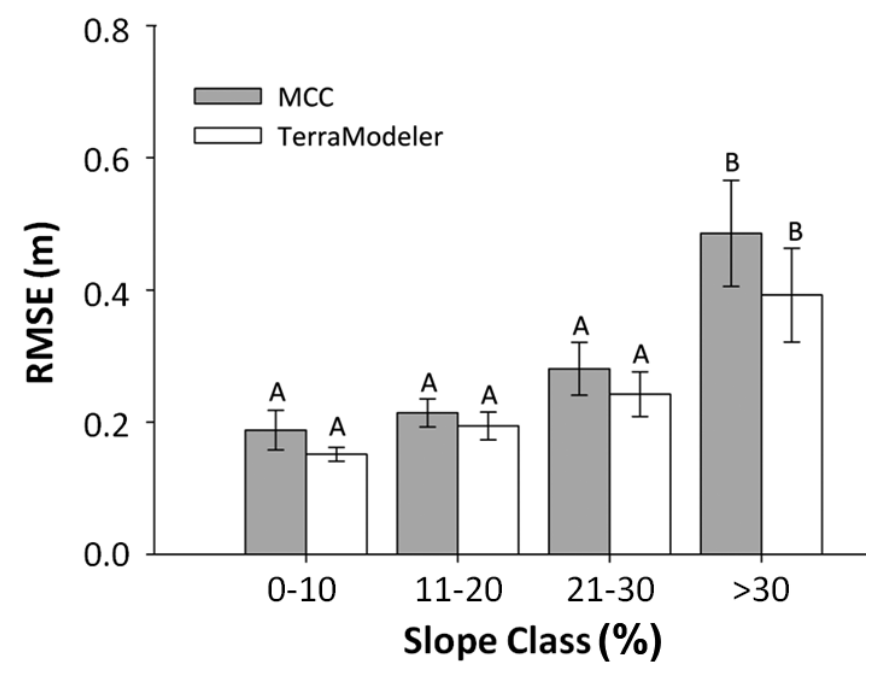

ity on higher slopes exceeding $20^{\circ}$ to $30^{\circ}$ slope where the level of variability in LiDAR accuracy increases at a steeper rate. This increase in error above $30^{\circ}$ could have implications when it comes to implementing LiDAR for forest inventory purposes. Although LiDAR has been demonstrated to be able to reasonably estimate tree heights in western forests under most conditions, estimations in areas of high slopes will have increased error due to the error introduced to the DEM. In areas of steep slopes, increased planimetric error causes increased DEM error and, therefore, increases the error of vegetation height estimates that are based on their relative elevation to the DEM. The effect of slope on RMSE influences the accuracy of LiDAR-derived variables in areas of high topographic relief common in the western United States and other mountainous regions.

To highlight the influence that vertical error in the DEM can have on timber volume estimation, timber volume $\left(\mathrm{m}^{3} \cdot \mathrm{ha}^{-1}\right)$ was calculated for four of the study plots representing different forest successional stages. Figure 6 shows the amount of relative error introduced into the volumetric estimation of timber based on the DEM errors from each of the four slope classes. The example takes the calculated volume of the example plots and calculates the potential influence of the slope by adjusting $( \pm)$ the tree heights by the mean 
Fig. 6. Error introduced from LiDAR DEM to timber volume estimation across four slope classes. Each stand represents a different successional stage.

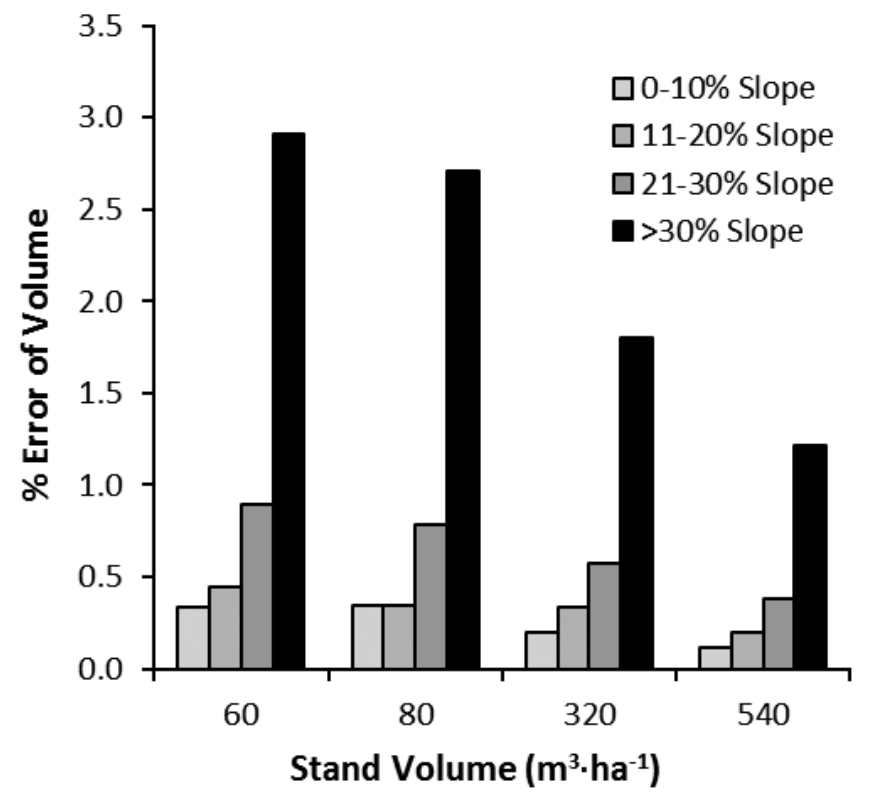

Table 4. Comparison of DEM accuracy above and below a $30^{\circ}$ slope.

\begin{tabular}{llllll}
\hline & \multicolumn{2}{l}{ MCC RMSE $(\mathrm{m})$} & & \multicolumn{2}{l}{ Vendor RMSE $(\mathrm{m})$} \\
\cline { 2 - 3 } \cline { 5 - 6 } & $<30^{\circ}$ & $>30^{\circ}$ & & $<30^{\circ}$ & $>30^{\circ}$ \\
& slope & slope & & slope & slope \\
\hline Mean & 0.242 & 0.493 & & 0.214 & 0.397 \\
Median & 0.223 & 0.395 & & 0.175 & 0.292 \\
SD & 0.121 & 0.321 & & 0.104 & 0.281 \\
Minimum & 0.096 & 0.177 & & 0.117 & 0.181 \\
Maximum & 0.589 & 1.321 & & 0.550 & 1.288 \\
\hline
\end{tabular}

Note: RMSE, root mean square error; SD, standard deviation.

RMSEs found for each of the four slope classes. From the example, it can be seen that the level of error introduced by the DEM in slope classes 1-3 does not exceed $1 \%$ of the estimated volume, whereas in class 4 , it approaches $3 \%$, with there being greater relative error in the younger successional stands. These increased errors on sites with high slopes $\left(>30^{\circ}\right)$ may prove to be limiting to the implementation of $\mathrm{Li}$ DAR for forest inventory in some regions.

It can be seen from the results of the ANOVA in Table 3 that there was no significant difference between the performances of each algorithm across the three canopy cover classes. Although further testing may be needed, this shows that both the open-source and proprietary algorithms were capable of handling the complex terrain and vegetation structure found within the study area. This indicates strong potential of open-source techniques to handle LiDAR processing of data taken from these complex forested environments.

Although past studies have provided us with knowledge of how terrain and vegetation interact to influence LiDAR DEM accuracy, little work has evaluated how different processing techniques perform under varying conditions. With much of
Fig. 7. The effect of LiDAR system horizontal error on vertical accuracy as it relates to terrain slope. Each line indicates a different level of terrain slope.

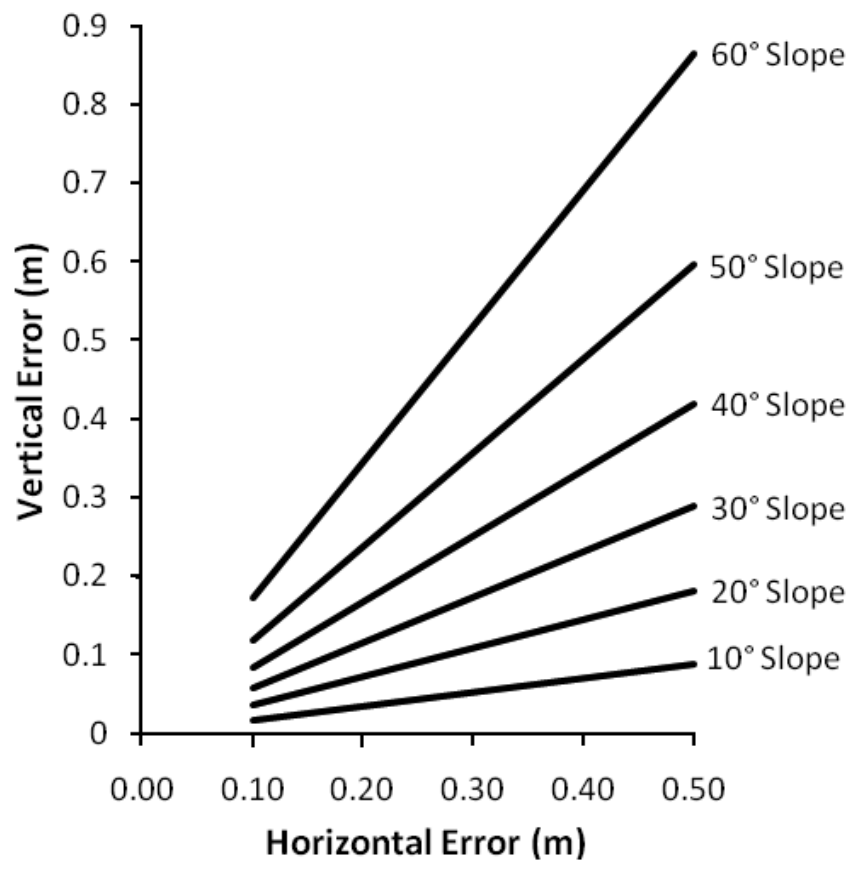

the western forested land being located on terrain that often exceeds $30^{\circ}$, it will be necessary to develop ways to account for associated error in LiDAR DEMs. Table 4 shows that RMSE doubles from plots on slopes $<30^{\circ}$ relative to those on slopes $>30^{\circ}$; this error would carry through to any forest inventory metric produced from this DEM, e.g., a canopy height model. Although these errors could be an artifact of the four slope classes used in the ANOVA, the increasing variability seen in Fig. 4 lends credence to there being greater variability in vertical accuracy above $30^{\circ}$ than there is below $30^{\circ}$. This variability in error can be partially attributed to inaccuracies in the LiDAR classification on steep slopes, although much of it is believed to be a result of horizontal beam divergence from the acquisition sensor. This introduced error from the acquisition instrumentation leads to increased vertical error variability at increased slopes. However, the influence of slope will be minimized as new LiDAR collection systems come online with narrower horizontal beam divergences, limiting the accuracy variability being introduced. Figure 7 illustrates the effect that horizontal divergence can have on the vertical accuracy of the LiDAR pulse. The vertical error introduced to LiDAR data by horizontal beam divergence can be significant, with different LiDAR acquisition systems having divergences ranging from 0.2 to $1.0 \mathrm{~m}$ from $2000 \mathrm{~m}$ above ground level. In comparing the impact of divergence for two systems with horizontal errors of 0.2 and $0.6 \mathrm{~m}$, respectively, on a $60^{\circ}$ slope, the vertical errors are 0.35 and $1.04 \mathrm{~m}$, respectively. Errors of this magnitude could carry potentially significant financial ramifications in the estimation of timber volume (Gatziolis et al. 2010). Yet looking at Fig. 6, the level of accuracy being achieved by these classification algorithms appears to have a minimal potential impact on timber volume estimates. Im- 
provements to the level of horizontal displacement seen in LiDAR collection systems have already been made and will continue, but these kinds of errors still need to be considered in steep terrain (Ussyhkin and Theriault 2011).

Although we acknowledge that the results presented herein are dependent on the specific LiDAR acquisition parameters, the results are broadly extendable to other studies, especially when acquisition parameters are similar. Indeed, the current study corroborated findings of prior studies in which higher slopes led to reduced DEM accuracy (Hodgson and Bresnahan 2004; Hyyppä et al. 2005; Su and Bork 2006) and increased uncertainty in resulting estimates of forest biophysical parameters (Gatziolis et al. 2010; Takahashi et al. 2005). Although we did not assess the influence of pulse density on DEM and forest biophysical parameters accuracy, prior work has demonstrated that increased point density can compensate for, or reduce, these errors (Liu et al. 2007); thus, we suggest that future LiDAR acquisitions could reduce slope-associated errors in forest biophysical parameters by selecting appropriate acquisition parameters (i.e., increased pulse density).

\section{Conclusions}

With the level of error introduced by the DEM on the estimated timber volume being $<3 \%$ in all conditions, LiDAR shows potential to be significantly more accurate than the $10 \%-20 \%$ often found to be acceptable in traditional forest inventory techniques, especially if forest allometric relations are developed that can directly utilize LiDAR-derived metrics. Given the inability of LiDAR to directly estimate diameter at breast height, which is critical in most traditional forest allometric relations, new LiDAR-friendly allometrics will need to consider utilizing metrics that can be derived from the LiDAR point cloud, e.g., distributions of the return heights. Although vegetative structure could not be shown to be a significant influence on DEM RMSE in this study, it is well known that different cover types can affect the density of ground returns, which in turn can affect DEM accuracies. However, in this study, it seems that both MCC and TerraModeler are able to handle the forested ecosystem being investigated. It is apparent that as system acquisition accuracy improves, these styles of algorithms will only improve in their capabilities and accuracies. As research continues to show the improved accuracy and capability of LiDAR, a broader acceptance of its ability to provide accurate threedimensional remotely sensed vegetation and terrain information will be seen crossing further into the management world.

\section{Acknowledgements}

This project would not have been possible without the funding that was provided by the Upper Midwest Aerospace Consortium (UMAC), which is, in turn, funded by NASA. Further support was provided by Potlatch Timber Company, through the use of their LiDAR data set, and financial contributions from the USDA Forest Service Rocky Mountain Research Station and Idaho Space Grant Consortium. The Topcon total station and other pieces of measurement equipment were purchased with funds provided by the NSF Idaho EPSCoR Program and NSF award number EPS-0814387.

\section{References}

Abermann, J., Fischer, A., Lambrecht, A., and Geist, T. 2010. Multitemporal airborne LiDAR-DEMs for glacier and permafrost mapping and monitoring. The Cryosphere, 4: 383-414.

Aguilar, F.J., and Mills, J.P. 2008. Accuracy assessment of LiDARderived digital elevation models. Photogramm. Rec. 23(122): 148169. doi:10.1111/j.1477-9730.2008.00476.x.

Asner, G.P. 2009. Tropical forest carbon assessment: integrating satellite and airborne mapping approaches. Environ. Res. Lett. 4(3): 034009. doi:10.1088/1748-9326/4/3/034009.

Axelsson, P.E. 1999. Processing of laser scanner data - algorithms and applications. J. Photogram. Remote Sens. 54(2-3): 138-147. doi:10.1016/S0924-2716(99)00008-8.

Bates, C.W., and Coops, N.C. 2009. Evaluating error associated with LiDAR-derived DEM interpolation. Comput. Geosci. 35(2): 289300. doi:10.1016/j.cageo.2008.09.001.

Bowen, Z.H., and Waltermire, R.G. 2002. Evaluation of light detection and ranging (LiDAR) for measuring river corridor topography. J. Am. Water Resour. Assoc. 38(1): 33-41. doi:10. 1111/j.1752-1688.2002.tb01532.x.

Brown, K.J., Snell, J.A.K., and Bunnell, D.L. 1977. Handbook for predicting slash weight of western conifers. USDA Forest Service Gen. Tech. Rep. INT-37. Available from http://www.fs.fed.us/rm/ pubs_int/int_gtr037.pdf [accessed 29 September 2009].

Cooper, S.V., Nieman, K.E., Steele, R., and Roberts, D.W. 1987. Forest habitat types of northern Idaho: a second approximation. USDA Forest Service Gen. Tech. Rep. INT-236.

Disney, M.I., Kalogirou, V., Lewis, P., Prieto-Blanco, A., Hancock, S., and Pfeifer, M. 2010. Simulating the impact of discrete-return LiDAR systems and survey characteristics over young conifer and broadleaf forests. Remote Sens. Environ. 114(7): 1546-1560. doi:10.1016/j.rse.2010.02.009.

Drake, N.A., Mackin, S., and Settle, J.J. 1999. Mapping vegetation, soil, and geology in semiarid shrublands using spectral matching and mixture modeling of SWIR AVIRIS imagery. Remote Sens. Environ. 68(1): 12-25. doi:10.1016/S0034-4257(98)00097-2.

Evans, J.S., and Hudak, A.T. 2007. A multiscale curvature algorithm for classifying discrete return lidar in forested environments. IEEE Trans. Geosci. Remote Sens. 45(4): 1029-1038. doi:10.1109/ TGRS.2006.890412.

Evans, J.S., Hudak, A.T., Faux, R., and Smith, A.M.S. 2009. Discrete return LiDAR in natural resources: recommendations for project planning, data processing, and deliverables. Remote Sens. 1(4): 776-794. doi:10.3390/rs1040776.

Falkowski, M.J., Smith, A.M.S., Hudak, A.T., Gessler, P.E., Vierling, L.A., and Crookston, N.L. 2006. Automated estimation of individual conifer tree height and crown diameter via twodimensional spatial wavelet analysis of LiDAR data. Can. J. Remote Sens. 32(2): 153-161. doi:10.5589/m06-005.

Falkowski, M.J., Wulder, M.A., White, J.C., and Gillis, M.D. $2009 a$. Supporting large-area, sample-based forest inventories with very high spatial resolution satellite imagery. Prog. Phys. Geogr. 33(3): 403-423. doi:10.1177/0309133309342643.

Falkowski, M.J., Evans, J.S., Martinuzzi, S., Gessler, P.E., and Hudak, A.T. 2009b. Characterizing forest succession with LiDAR data: an evaluation for the Inland Northwest, USA. Remote Sens. Environ. 113(5): 946-956. doi:10.1016/j.rse.2009.01.003.

Flood, M. (Editor). 2004. ASPRS guidelines vertical accuracy reporting for LiDAR data. Amer. Soc. Photogram. Remote Sens. LiDAR Committee. Ver. 1. Available from http://www.asprs.org/ a/society/committees/lidar/Downloads/Vertical_Accuracy_Reporting for_Lidar_Data.pdf [accessed 24 June 2011].

Frazer, G.W., Canham, C.D., and Lertzman, K.P. 1999. Gap Light Analyzer (GLA). Version 2.0. Imaging software to extract canopy 
structure and gap light transmission indices from true-color fisheye photographs. Copyright 1999. Simon Fraser University, Burnaby, B.C., and the Institute of Ecosystem Studies, Millbrook, New York. Available from http://www.rem.sfu.ca/forestry/publications/ downloads/gaplightanalyzer.htm [accessed 28 September 2009].

Gatziolis, D., Fried, J.S., and Monleon, V.S. 2010. Challenges to estimating tree height via Lidar in closed-canopy forests: a parable from western Oregon. For. Sci. 56(2): 139-155.

Goodwin, N.R., Coops, N.C., and Culvenor, D.S. 2006. Assessment of forest structure with airborne LiDAR and the effects of platform altitude. Remote Sens. Environ. 103(2): 140-152. doi:10.1016/j. rse.2006.03.003.

Hitchcock, C.L., and Cronquist, A. 1979. Flora of the Pacific Northwest. University of Washington Press, Seattle, Washington.

Hodgson, M.E., Jensen, J., Raber, G., Tullis, J., Davis, B.A., Thompson, G., and Schuckman, K. 2005. An evaluation of LiDAR-derived elevation and terrain slope in leaf-off conditions. Photogram. Eng. Remote Sens. 71(7): 817-823. Available from http://www.asprs.org/a/publications/pers/2005journal/july/2005_ july_817-823.pdf [accessed 15 October 2009].

Hodgson, M.E., and Bresnahan, E. 2004. Accuracy of airborne LiDAR-derived elevation: empirical assessment and error budget. Photogram. Eng. Remote Sens. 70(3): 331-339. Available from http://www.asprs.org/a/publications/pers/2004journal/march/2004_ mar_331-339.pdf [accessed 15 October 2009].

Hudak, A.T., Evans, J.S., and Smith, A.M.S. 2009. LiDAR utility for natural resource managers. Remote Sens. 1(4): 934-951. doi:10. 3390/rs1040934.

Hyyppä, H., Yu, X., Hyyppä, J., Kaartinen, H., Kaasalainen, S., Honkavaara, E., and Rönnholm, P. 2005. Factors affecting the quality of DTM generation in forested areas. In ISPRS WG III/3, III/4, V/3 Workshop, Laser scanning 2005, Enschede, Netherlands, 12-14 September 2005. Remote Sens. and Spatial Info. Sci. (Part 3/W19). pp. 97-102. Available from www.helsinki.fi/ korpela/ MINV12/DTM_accuracy.pdf [accessed 8 October 2009].

Jensen, J.R. 2007. Remote sensing of the environment: an Earth resource perspective. Prentice Hall, Upper Saddle River, New Jersey.

Liu, X., Zhang, Z., Peterson, J., and Chandra, S. 2007. The effects of LiDAR data density on DEM accuracy. In MODSIMO7 International Congress on Modeling and Simulation, 10-13 December 2007, Christchurch, New Zealand. Available from http://eprints.
usq.edu.au/3781/1/Liu_Zhang_Peterson_Chandra.pdf [accessed 10 October 2009].

Martinuzzi, S., Vierling, L.A., Gould, W.A., Falkowski, M.J., Evans, J.S., Hudak, A.T., and Vierling, K.T. 2009. Mapping snags and understory shrubs for a LiDAR-based assessment of wildlife habitat suitability. Remote Sens. Environ. 113(12): 2533-2546. doi:10.1016/j.rse.2009.07.002.

Reutebuch, S.E., McGaughey, R.J., Andersen, H.-E., and Carson, W.W. 2003. Accuracy of a high-resolution lidar terrain model under a conifer forest canopy. Can. J. Remote Sens. 29(5): 527535. doi:10.5589/m03-022.

Rustagi, K.R., and Loveless, R.S., Jr.. 1991. Compatible variableform volume and stem-profile equations for Douglas-fir. Can. J. For. Res. 21(2): 143-151. doi:10.1139/x91-018.

Smith, A.M.S., Falkowski, M.J., Hudak, A.T., Evans, J.S., Robinson, A.P., and Steele, C.M. 2009. A cross-comparison of field, spectral, and lidar estimates of forest canopy cover. Can. J. Remote Sens. 35(5): 447-459. doi:10.5589/m09-038.

$\mathrm{Su}$, J., and Bork, E. 2006. Influence of vegetation, slope, and LiDAR sampling angle on DEM accuracy. Photogram. Eng. Remote Sens. 72(11): 1265-1274. Available from http://www.asprs.org/a/publications/pers/2006journal/november/2006_nov_1265-1274.pdf [accessed 12 October 2009].

Takahashi, T., Yamamoto, K., Senda, Y., and Tsuzuku, M. 2005. Estimating individual tree heights of sugi (Cryptomeria japonica D. Don) plantations in mountainous areas using small-footprint airborne LiDAR. J. For. Res. 10(2): 135-142. doi:10.1007/ s10310-004-0125-8.

Theseira, M.A., Thomas, G., Taylor, J.C., Gemmell, F., and Varjo, J. 2003. Sensitivity of mixture modeling to end-member selection. Int. J. Remote Sens. 24(7): 1559-1575. doi:10.1080/ 01431160210146631.

Tinkham, W.T., Huang, H., Smith, A.M.S., Shrestha, R., Falkowski, M.J., Hudak, A.T., Link, T.E., Glenn, N.F., and Marks, D.G. 2011. A comparison of two open source lidar surface classification algorithms. Remote Sens. 3(3): 638-649. doi:10.3390/rs3030638.

Ussyshkin, V., and Theriault, L. 2011. Airborne Lidar: advances in discrete return technology for $3 \mathrm{D}$ vegetation mapping. Remote Sens. 3(3): 416-434. doi:10.3390/rs3030416.

Wessman, C.A., Bateson, C.A., and Benning, C.L. 1997. Detecting fire and grazing patterns in tallgrass prairie using spectral mixture analysis. Ecol. Appl. 7(2): 493-511. doi:10.1890/1051-0761 (1997)007[0493:DFAGPI]2.0.CO;2. 